which he addressed to the Academy of Medicine and Sciences.

"I-Complete immunity from cholera of the immense majority of all workmen whose calling necessitates their being habitually in contact with copper dust.

"2-Copper and its alloys, brass and bronze, permanently applied to large surfaces of the common integument, are a most precious preventative, which ought in no wise to be neglected and can cause no inconvenience. If these means leave something to be desired as a prophylactic, it will probably be found expedient to reduce the metal to an impalpable powder and to ingest a few pinches.

"3-In the treatment of cholera, copper, opportunely administered, whether in copper filing alone or in any other form which experience shall determine, affords the greatest probability of proving in the hands of the physician a powerful means of cure."

Having been convinced that even in fairly large doses copper sulfate is harmless to the human system, I tried its germicidal effect in the Taylor Gymnasium pool. As. the pool water at the time was being refiltered daily, a small amount of alum being added to aid the mechanical filter-I took the opportunity of first determining the efficiency of the alum treatment. As the copper treatment immediately followed the alum treatment, I have tabulated my results together.

Table III shows the results of the use of alum and of alum and copper sulfate.

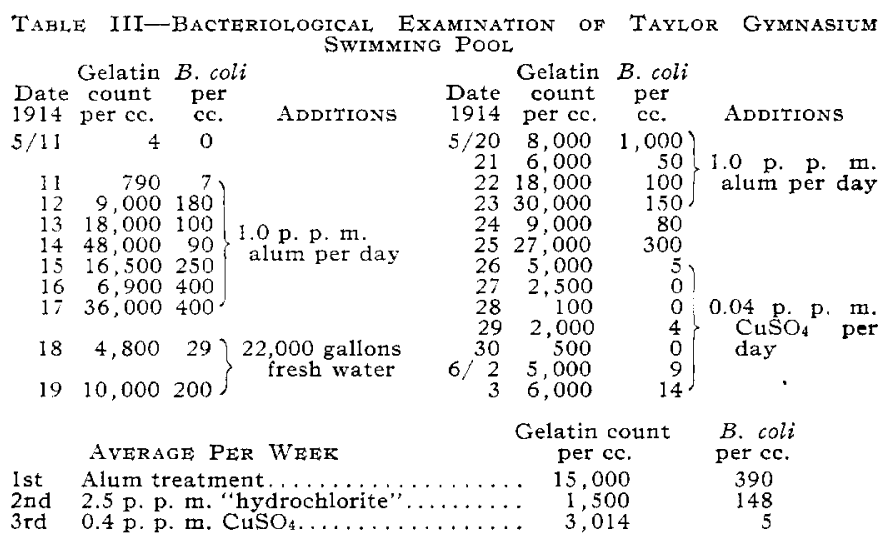

Although copper sulfate is slightly more expensive than hypochlorite of lime, about $\$$ r.0o per hundredweight, it is effective in much smaller quantities and hence is cheaper to use.

The germicidal action of the copper sulfate is probably that of a crystalloid, permeating the cell wall and thereby producing the toxic effects.

In the presence of the bicarbonate of magnesium and calcium the following reaction takes place:

$\mathrm{CuSO}_{4}+\mathrm{Ca}\left(\mathrm{HCO}_{3}\right)_{2}=\mathrm{CaSO}_{4}+\mathrm{Cu}(\mathrm{OH})_{2}+{ }_{2} \mathrm{CO}_{2}$

This chemical change, while it destroys the toxic power of the salt, really aids in the ultimate purification of the water since the hydroxide formed acts as a coagulant uniting with the suspended organic matter.
STMIIARY

The advantages of copper sulfate over hypochlorite of lime as a disinfectant for swimming pools therefore may be summarized as follows:

I-It is more effective because it does not undergo chemical change readily. Hypochlorite owes its power to the chemical change and is afterwards useless.

II-It is not irritating to the eyes and mucous membranes as is "hypochlorite" if the latter is used in germicidal quantities.

III-It is cheaper.

IV-It has no odor. If all other conditions were equal this last fact alone would prove its great advantage over "hypochlorite."

DEPARTMENT OF BIOLOGY, LEHIGH UNIVERSTTY SOUTH BeThLEHEM, PA.

\section{THE VALUATION OF COMMERCIAL ARSENATE OF LEAD}

By R. H. ROBINSON AND H. V. TARTAR

Received January 16, 1915

The practical value of the arsenates of lead as insecticides depends upon their arsenic content and their comparative insolubility in water which prevents them from being injurious to foliage. There are three arsenates known: the lead of hydrogen or "acid" arsenate, the basic or "neutral" arsenate, and the pyroarsenate. The latter salt is unimportant from a spray standpoint, since it is probably not present in the commercial brands upon the market, due to the fact that the pyro salt cannot exist in the presence of water and, thus far, has been prepared only by heating the pure hydrogen arsenate at high temperatures as shown by Tartar and Robinson. ${ }^{1}$ Previous investigations by Tartar and Robinson ${ }^{1}$ have shown that pure lead hydrogen arsenate can be prepared corresponding in composition to the theoretical formula $\mathrm{PbHAsO}_{4}$, giving upon analysis 32.98 per cent arsenic oxide and 63.92 per cent lead oxide. The basic arsenate was also found to be of constant composition when prepared from pure salts and gave upon analysis 23.42 per cent arsenic oxide and 74.72 per cent lead oxide.

Practically, then, there are two kinds of lead arsenates: (I) the hydrogen, and (2) the basic arsenate generally used as a spray material; manufacturers of commercial brands usually produce one or the other form and label them as such. The hydrogen arsenate is found on the market under the trades name "acid" or "dibasic" arsenate of lead and the basic is commonly known as the "neutral," "triplumbic" or "tribasic" arsenate of lead. There are, however, many brands that do not specify either a hydrogen or a basic sample but are simply labeled "arsenate of lead."

In the analysis of the commercial brands of lead arsenates, the specific determinations usually required, as evidence that the product is not a violation of the Federal Insecticide Law, consist of an estimation of total arsenic oxide, total lead oxide, water-soluble arsenic oxide, and moisture. This is sufficient to ascertain whether the sample fulfills the requirements as demanded by law, but it does not give evidence of the exact nature of the sample.

1 Tartar and Robinson, J. A. C. S., 36 (1914), 1843. 
For the true valuation of these commercial samples, therefore, method's for their complete analysis are necessary. It is not enough to know the total arsenic or lead content to ascertain the value of the spray material as an insecticide, but it is equally important to understand the forms in which these elements are combined, and to what extent they exist as such. For example, if a sample is found to contain lead combined in the form of the basic or hydrogen arsenate, the carbonate and the chloride, the proportion and the extent to which each compound is present is an important consideration, and the estimation of each of these forms is essential in the valuation of the insecticide. Any other substance or impurity that would also depreciate the value of the sample is a factor in its valuation. These impurities such as carbonates, chloride, acetates, water-soluble substances, etc., besides being adulterants may have an injurious effect upon foliage and hence depreciate the intrinsic value of the material as a spray. Haywood and McDonnell ${ }^{1}$ have shown that the chlorides, sulfates, and carbonates of the alkali metals render the arsenic in certain varieties of commercial lead arsenate more soluble, and hence increase the liability to foliage injury. In order to make these estimations, new methods were devised at this Station and substituted in some cases where the old ones were found to be inaccurate. Comparisons of the methods employed are given in Table $\mathrm{I}$.

It can be understood, after a consideration of the possibilities for the introduction of impurities and the existence of both arsenic and lead in different proportions to form several compounds, that the insecticidal values of various commercial arsenates are appreciably different. Recent investigations by $\mathrm{H}$. F. Wilson, ${ }^{2}$ Entomologist of this Experiment Station, have shown that the arsenates of lead have widely different insecticidal properties. The pure lead hydrogen arsenate, specially prepared in this laboratory, was found to kill more quickly, to remain in suspension longer and to be more easily applied. From what has been stated regarding impurities and the differences in the constitutions of the lead arsenates, it is of paramount importance to ascertain, as far as possible, the true nature of the commercial arsenates.

In view of the possibilities for the introduction of impurities and adulterations and the existence of the two arsenates in one product, a number of commercial samples were selected and a system for their total analysis devised. The following determinations were made: Moisture, total arsenic oxide, total lead oxide, lead hydrogen arsenate, water-soluble arsenic oxide and lead oxide, lead carbonate, water-soluble impurities, chlorides, sulfates, acetates, and acid-insoluble impurities. In order to make these determinations it was necessary to devise several new methods and change some of the old ones now in use.

ANALYTICAL METHODS USED

For the determination of moisture, total arsenic

1 United States Department of Agriculture, Bureau of Chemistry, Bull. 131, 46 .

2 Proceedings of the Entomological Society of British Columbia, July, 1913, p. 9. oxide, and total lead oxide, the official method as outlined in Bureat of Chemistry Bull. I07, 239, was found satisfactory.

Water-soluble arsenic oxide and lead oxide were determined by two different methods, one being the regular official method as given in Bureau of Chemistry Bull. 107, 240, and the other devised at this Station which for convenience is designated as the "Oregon Station Method." This method is based upon the extreme insolubility of both hydrogen and neutral arsenates as shown by Tartar and Robinson. ${ }^{1}$ It is carried out as follows: A convenient amount, 4 to 6 grams, of the sample is accurately weighed out and transferred to a $590 \mathrm{~S}$. \& S. filter paper, first macerating in a mortar with a little water until it has a consistency that permits pouring onto the filter. Distilled water is used to extract the soluble arsenic oxide and lead oxide. (It is imperative that no carbonic acid nor ammonia be present in the water as they may react with lead arsenate, liberating arsenic in a soluble form.) The water-soluble impurities are extracted from the sample by washing with hot water until about a liter of filtrate is obtained. It is then cooled, made up to rooo cc. and an aliquot titrated with standard iodine solution after reduction with potassium iodide according to modified Gooch and Browning method. Should the filtrate come through cloudy it may be clarified by filtering through a Gooch, that has a thin layer of pure carbon black over the asbestos pad.

In the estimation of the amount of lead hydrogen arsenate in the presence of the basic salt, it is first necessary to remove any water-soluble arsenic oxide that may be present. Consequently, the residue, obtained by leaching the sample with hot water, in the Oregon Station method above, was used. The determination was then made by the method devised by Tartar and Robinson. ${ }^{1}$

Water-soluble solids or impurities were also determined by two different methods. In one case the official method as outlined in Bureau of Chemistry Bull. 107, 240, was applied. In the other method employed, $200 \mathrm{cc}$. of the clear filtrate, obtained in the Oregon Station method for the water-soluble oxide and lead oxide as cited above, were evaporated to dryness in a platinum dish upon a steam bath, dried at I $10^{\circ} \mathrm{C}$. and weighed. This gave the amount of watersoluble solids including foreign impurities and the soluble arsenic oxide.

Lead carbonate was calculated from the amount of carbon dioxide found in the sample, the Bowser method $^{2}$ being used as a basis for the determination of the carbon dioxide. The procedure, revised and made applicable to lead arsenate, is briefly as follows: An apparatus similar to that described by Bowser is used. About Io grams of the sample are introduced into an Erlenmeyer flask of $200 \mathrm{cc}$. capacity, and 50 cc. of water added and, after inserting the rubber stopper through which a thistle tube passes, about $5 \mathrm{cc}$. of concentrated hydrochloric acid are allowed to

1 Loc. cit.

2 This Journat, 4 (1912), 203. 
run in. The absorbing tower contains $5 \mathrm{cc}$. of a 50 per cent solution of potassium hydroxide. When all connections are secure a low flame is applied and about $25 \mathrm{cc}$. distilled over, titrated with normal acid to disappearance of the pink color of the phenolphthalein indicator, and finally with $O . I N$ acid to neutrality with methyl orange indicator. Each cc. of O.I $N$ acid used in the final titration is equivalent to 0.0267 gram of lead carbonate, ${ }^{1} \mathrm{PbCO}_{3}$.

The acid-insoluble substances were estimated by dissolving Io grams of the dry material in warm dilute nitric acid, Io per cent strength. The insoluble matter was collected upon a Gooch, washed free of acidity, dried at $I 10^{\circ} \mathrm{C}$. and weighed.

Chlorides were determined as follows: A convenient amount of the sample, usually 4 grams, was dissolved in warm dilute nitric acid and the insoluble impurities filtered off. Excess of standard silver nitrate was added to the filtrate and titration completed as in the Volhard method for the chlorine.

Acetates were tested for qualitatively by converting them into ethyl acetate and observing the characteristic odor. This was performed as follows: A convenient amount of sample was added to a hot solution of $5 \mathrm{cc}$. of sulfuric acid and $5 \mathrm{cc}$. of 95 per cent alcohol. This was then brought to a boil brands contain small amounts of lead carbonate, free-arsenic oxide, and water-soluble impurities, the small extent to which these substances are present are indications of a fair product. Attention is called especially to Samples 4 and 5 which demonstrate the value and applicability of methods devised at this Station. Both of these arsenates contain a very high percentage of lead carbonate and soluble impurities. Sample 4 contains no lead combined as the hydrogen arsenate. Furthermore, since the ratio of total arsenic oxide to total lead oxide in the pure basic arsenate is I : 3.I9, this sample shows a large excess of lead oxide. This excess could not be accounted for were it not for the detection and quantitative estimation of the lead carbonate in the sample. The absence of water-soluble arsenic oxide should also be noted: obviously this might be expected from a mixture of basic lead arsenate and lead carbonate, for the presence of lead in the above form would perhaps combine with any free arsenic acid, resulting in the formation of an insoluble arsenate. In fact, the absence of watersoluble arsenic oxide in neutral arsenates generally has been demonstrated by analyses of many samples received in this laboratory. Sample 5, on the other hand, is not a lead hydrogen arsenate since the ratio of tolal arsenic oxide to lead oxide is greater than that in

Table I-Percentage Axalyses of Samples of Commercial Lead Arsenate

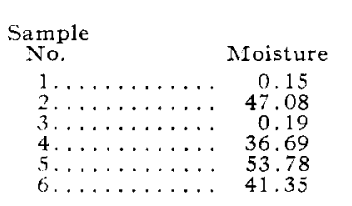

Total
$\mathrm{As}_{2} \mathrm{O}_{5}$
32.53
15.07
31.47
12.34
12.01
16.19

Total
PbO
63.50
34.71
64.02
46.58
30.55
31.64

Total
PbHAsO4
99.38
30.17
92.01
Trace
18.01
55.97

Water solu
Official
0.08
0.08
Trace
Trace
0.77
Trace

when, in the presence of an acetate, the characteristic odor of ethyl acetate is obtained. Should there be any free acetic acid in the sample it may be leached out with hot water and the acidity titrated against standard sodium hydroxide solution, using phenolphthalein as indicator.

The different commercial samples used as exemplary specimens were selected in such a manner that a representative product as manufactured by various firms was secured. Two of the six samples so obtained were the dry powdered type recently placed upon the market and the other four were the usual paste arsenates.

A total analysis of the several brands of commercial lead arsenate is given in Table $I$.

An examination of Table I as a whole shows that the commercial arsenates of lead differ to a considerable extent in their chemical composition. From the analysis, Samples I and 6 show the highest degree of purity, the former being almost a pure hydrogen arsenate in the powder form, while the latter is the same kind in the paste form. The small amounts of impurities present further indicate the high grade of both of these products. Samples 2 and 3 are mixtures of the hydrogen and basic salts, the hydrogen arsenate predominating in the former sample, and the basic arsenate in the latter. Although both of these

1 The lead may be otherwise combined than the normal carbonate but since the exact form was not ascertained it is reported as $\mathrm{PbCO}_{3}$.

\begin{tabular}{|c|c|c|c|c|c|c|}
\hline \multirow{2}{*}{$\begin{array}{l}\text { As } \mathrm{As}_{2} \mathrm{O} \\
\text { Oregon } \\
\text { Station }\end{array}$} & \multirow[b]{2}{*}{$\begin{array}{l}\text { Lead } \\
\text { carbonate }\end{array}$} & \multirow[b]{2}{*}{$\begin{array}{l}\text { Insoluble } \\
\text { substance }\end{array}$} & \multirow[b]{2}{*}{ Chlorine } & \multicolumn{2}{|c|}{ Water- } & \multirow{2}{*}{$\begin{array}{l}\text { Water- } \\
\text { soluble } \\
\text { Pbo }\end{array}$} \\
\hline & & & & Official & $\begin{array}{l}\text { Oregor } \\
\text { station }\end{array}$ & \\
\hline 0.12 & Tone & 0.08 & None & 0.25 & 0.40 & None \\
\hline 0.15 & 0.30 & 0.04 & 0.22 & 0.35 & 0.94 & None \\
\hline Trace & 0.48 & 0.13 & None & 0.55 & 0.71 & None \\
\hline Trace & 16.57 & 0.02 & 0.06 & 0.52 & 0.93 & None \\
\hline 1.12 & 9.90 & 0.22 & 0.10 & 3.66 & 4.28 & None \\
\hline Trace & None & 0.04 & None & 0.25 & 0.55 & None \\
\hline
\end{tabular}

the pure salt which is I : I.9. Analysis shows, furthermore, that this excess of lead oxide is present in the form of the carbonate. Inlike Sample 4 , it has an extraordinary amount of water-soluble arsenic oxide.

At this point, it might be well to make a comment upon the requirements of the Federal Insecticide Law with reference to the arsenates of lead. In brief, the requirements are: "It must not contain: (I) more than 50 per cent of water; (2) less than I2.5 per cent of arsenic oxide, $\mathrm{As}_{2} \mathrm{O}_{5}$; (3) more than 0.75 per cent of water-soluble arsenic oxide, $\mathrm{As}_{2} \mathrm{O}_{5}$." As stated above, the pure hydrogen arsenate as prepared in the laboratory, contains 32.98 per cent total arsenic oxide, and in the basic or neutral salt there is 23.42 per cent arsenic oxide, these being the highest per cents possible in a pure sample. On a 50 per cent water basis, therefore, the maximum amount of arsenic oxide possible in a hydrogen arsenate is 16.49 per cent and in the basic compound II.7 I per cent. Hence, it is plainly evident that the law was made without a sufficient knowledge of the exact composition of the two types of lead arsenates, for no manufacturer could make a neutral arsenate that contains 12.5 per cent total arsenic oxide on a 50 per cent water basis when the pure product as prepared in the laboratory could contain at the most only II.7 I per cent. In order to abide by the law, therefore, it would be necessary to reduce the moisture 
or increase the arsenic oxide by some means. To obviate this difficulty, therefore, a maximum per cent of total arsenic oxide in hydrogen or acid arsenate should be specified and another amount for the neutral or basic arsenate.

A comparison of the amounts of water-soluble arsenic obtained by each method shows that the greater percentage is always found by the Oregon Station method. From these figures it is obvious that all the water-soluble arsenic oxide is not obtained by the official method; nor are the results obtained by the Oregon Station method too high, due to possible hydrolysis or other chemical action upon the sample, for in the three cases, Samples 3,4 and 6, where only a trace is reported present by the official method, identical results are obtained by the Oregon Station method. These latter results further substantiate the claim made in our previous paper that the pure arsenates of lead are extremely insoluble, and when there is any free-arsenic oxide found it is due to the arsenic being in the form of a soluble salt and not in the form of either the hydrogen or basic arsenate. It should also be noted that no soluble lead oxide was found by either method, which is further proof that the water-soluble arsenic oxide was not in the form of a soluble lead salt.

As additional proof that all the water-soluble arsenic oxide is not obtained by the official method, a glance at the two columns depicting the quantity of water-soluble solids or impurities found shows that the greater amount is consistently obtained by the Oregon Station method. It is quite evident from this that all soluble material is not taken out by the ordinary official method as outlined in Bureau of Chemistry Bull. 107. In all cases here cited it is shown that the amount obtained by the Oregon Station method is nearly double that obtained by the official method. It is possible that in the official method the soluble substances present remained occluded or adsorbed by the arsenate of lead and were not removed by water at room temperature. If, however, successive portions of hot water are used as in the Oregon Station method, this difficulty is overcome and the soluble salts go into solution. In the samples listed in Table I, soluble impurities, in all probability, are composed of chiefly sodium and potassium arsenate since qualitative tests show the presence of these two bases. Other impurities than those found are probably due to impurities in the materials used in the preparation of the commercial arsenate.

Chlorides were found in three of the samples examined. In two of these cases the quantity present was in amounts worthy of note.

The per cent of acid-insoluble impurities in the six samples cited is negligible but these impurities should not, however, be considered an unimportant constituent, as other samples received in this laboratory have shown as high as 5 per cent acid-insoluble material. When present to that extent it is an adulterant of no small consideration.

The tests for the presence of acetates, and sulfates likewise, gave negative results in these six samples.
Other arsenates, analyzed previously in this laboratory, however, have shown that these substances are sometimes present to an extent that would depreciate the value of the arsenate as an insecticide. The detection and estimation of these impurities may be valuable because their presence with the arsenates of lead results in the liberation of water-soluble arsenic oxide.

\section{SUMMARY}

I-The necessity of more complete methods for the true valuation of commercial lead arsenates has been pointed out.

II-Satisfactory methods have been worked out and applied to commercial samples as follows:

I-Estimation of lead hydrogen arsenate in presence of the mixed salts.

2-The determination of lead carbonate.

3-New methods for water-soluble arsenic oxide and water-soluble impurities.

4-A method for acid-insoluble impurities.

5 -The detection of acetates and the quantitative estimation of chlorides.

III-The application of these methods shows a wide variation in the composition of the commercial arsenates and gives a better valuation of them than the methods now in use.

IV-Comments have been made upon the inconsistencies of the Federal Insecticide Law.

Chemical, Laboratory
OREgon Agricuitural EXPERIMENT Station CoRvallis

\section{A STUDY OF VAPORS FROM DRYING PAINT FILMS}

By H. H. KiNG

Received April 10, 1915

In a recent article appearing in THIs JourNal, ${ }^{1}$ Mr. C. A. Klein, of Middlesex, England, criticized very severely an article communicated by Mr. H. A. Gardner, ${ }^{2}$ of Washington. Mr. Gardner's communication contained the result of an investigation as to the "Composition of Paint Vapors."

It cannot be denied that the method of procedure in some instances was open to adverse criticism. Particularly is this the case in the method employed for determining carbon monoxide. In Gardner's method the vapors coming from the drying oil films were conducted first through fuming sulfuric acid, and the carbon monoxide then determined by passing the gases through heated iodine pentoxide. It is a fairly well-established fact that linseed oil films give off formic acid in drying and since fuming sulfuric acid decomposes this acid, setting carbon monoxide free, any conciusion that the monoxide determined has come from the drying films alone must be lacking in absolute accuracy. The point brought out by Klein on this is well taken.

The present writer has been investigating for eighteen months the vapors coming from different drying oils when ground with different kinds of pigments, and had detected very small quantities of carbon

1 This Journal, 7 (1915), 99.

2Ibid., 6 (1914), 91. 